\title{
FACTORS AFFECTING THE MECHANICAL PROPERTIES OF COMPACT BONE AND MINIATURE SPECIMEN TEST TECHNIQUES: A REVIEW
}

\author{
Vandana Chittibabu', Korada Santa Rao', Potnuru Govinda Rao' \\ 1 Department of Mechanical Engineering, GMR Institute of Technology, Rajam, Andhra Pradesh, India, e-mail: \\ govind09.p@gmail.com
}

Received: 2016.08.17

Accepted: 2016.10.08

Published: 2016.12.01

\begin{abstract}
This paper presents the review concerning mechanical properties of bone and the miniature specimen test techniques. For developing a realistic understanding of how factors such as moisture content, mineralization, age, species, location, gender, rate of deformation etc. affect the mechanical properties of bone, it is critical to understand the role of these factors. A general survey on existing research work is presented on this aspect. The essential features of miniature specimen test techniques are described, along with the application of small punch test method to evaluate the mechanical behavior of materials. The procedure for the determination of tensile and fracture properties, such as: yield strength, ultimate strength, ductility, fracture toughness etc. using small punch test technique have been described. The empirical equations proposed by various investigators for the prediction of tensile and fracture properties are presented and discussed. In some cases, the predictions of material properties have been essentially made through the finite element simulation. The finite element simulation of miniature specimen test technique is also covered in this review. The use of inverse finite element procedure for the prediction of uniaxial tensile constitutive behaviour of materials is also presented.
\end{abstract}

Keywords: mechanical properties, compact bone, miniature specimen, small punch test, finite element simulation and inverse finite element procedure.

\section{INTRODUCTION}

Bone mechanical properties have been an important topic of study for many years. Thus, from a materials science perspective, understanding the mechanical properties of bone becomes a matter of paramount significance in order to develop a synthetic bone substitute with load bearing capability. Understanding mechanical properties of bone also enables more accurate models for analysis of implants and prospective bone-replacement materials. Biological hard materials like bones are difficult to test mechanically in standard sizes because they come in small pieces and awkward shapes. These constraints may be overcome by employing miniature specimens for mechanical testing. The advantage of such miniature specimens includes the possibility of sampling very small volume of material within a heterogeneous structure such as cortical bone. This may also be used for studying biological materials that are not available in large enough volumes for conventional mechanical testing. Miniature specimen test technique has emerged to solve this practical problem. To date, the mechanical behavior of cortical bone has not been described by using miniature specimen technique which is very handy in describing the mechanical behavior of metallic alloys. Therefore a study has been proposed for the characterization of bovine cortical bone using miniature specimen testing. This technique is especially useful in evaluating the properties in transverse direction of 
the bone as it is very difficult to extract specimens in the transverse direction because of the size and shape limitations.

\section{FACTORS AFFECTING THE MECHANICAL PROPERTIES OF COMPACT BONE}

\section{Effect of Moisture Content and Mineralization}

Moisture and mineralization are the major factors affecting the mechanical behavior of compact bone tissue. Melnis et al. [59] studied the nature of relationship between stress and deformation which permits evaluation of the degree of nonlinearity of the mechanical properties of bone tissue and the effect of moisture conditions and various other factors on the behavior of bone under stress. The samples were selected for study from the middle region of diaphysis of the tibia of five males from 20 to 30 years of age who had died in accidents. The samples were studied along the longitudinal axis of the bone dissected in the form of plates.

Currey [24] reported that the post-yield behavior of the least and the highly mineralized specimens differ greatly. He observed that in highly mineralized specimens the stress-strain curve is almost flat in the post-yield region where as in the less mineralized specimens, the stress continued to increase quite markedly with the strain.

In the work reported by Martin [57], the mechanical properties were assumed to depend on the composition (porosity and mineralization) and organization (trabecular or cortical bone architecture, collagen fiber orientation, fatigue damage) of the bone. He reviewed the possible means of noninvasively estimating the strength or other mechanical properties of a bone, employing quantitative computed tomography, photon absorptiometry and ultrasonic measurements. It is reported that the strength and stiffness decrease with increasing porosity. Various relationships between Young's Modulus and porosity proposed by different investigators were also given. The other factor which influences the bone mechanical properties is mineralization. The latter is defined as the ratio of ash mass to dry mass. Many studies reported a linear or exponential increase in bone's Young's Modulus with increasing mineralization. It is also observed that the two regions of the bone having similar porosity and mineralization may still have different material properties because of the organizational variability of the solid matrix of the bone.
Nyman et al. [24] studied the effect of water removal on the strength and toughness of cortical bone. They observed that loss of water in the collagen phase decreased the toughness of bone, whereas loss of water associated with the mineral phase decreased both bone strength and toughness.

Recently Kotha and Guzelsu [45] compared the mechanical behavior of bovine bone with the mechanical behavior of bones with less mineral content obtained by fluoride treatment. They reported an increase in elastic modulus, yield strength and ultimate tensile stress and a decrease in yield strain and ultimate strain with the increase in bone mineral content.

\section{Effect of Age}

Aging related changes to the musculoskeletal system are known to increase the susceptibility of bone fracture and in the case of very elderly persons; consequent fractures can lead to mortality. To characterize the deterioration of bone with age, most studies have utilized the fracture toughness or the strain energy release rate as a single parameter approach to characterize the resistance to fracture.

Vinz [85] examined mechanical properties of compact bone tissue of the human femur in different age groups. For the mechanical tests, about 200 samples of bone tissue were prepared from the middle section of the femur taken from 48 individuals consisting of seven age groups ranging from 0.1 to 100 years. Following kind of age dependences were noted:

- The ultimate tensile strength increases from $55 \mathrm{MPa}$ in the newborns to $104 \mathrm{MPa}$ in the adults and then drops to $82 \mathrm{MPa}$ in the aged persons.

- The modulus of elasticity E increased from 11 $\mathrm{GPa}$ in the new born to $35 \mathrm{GPa}$ in the adults and drops to $23 \mathrm{GPa}$ in the aged persons.

Courtney et al. [21] observed that the agerelated differences in post-yield behavior of human cortical bone were associated with increase in damage in the form of micro cracks. They also found that the mechanical properties from elderly femora were reduced compared to those from young adult femora. They reported that specimens from elderly femora had more micro cracks per unit area than those from young adult femora. Stein et al. [80] investigated age-related and gender related differences in bone size and bone mechanics at the femoral diaphysis. They 
found that older individuals had bones of greater external dimension than younger subjects. They also observed that cortical bone area was highest in young adulthood and lower in old age. Wang et al. [86] studied the age related changes in the toughness of bone. They found that the change in the integrity of collagen with age was responsible for the decreased toughness of aged bone.

\section{Effect of Gender}

Martin et al. [58] reported that the material strength of femoral bone decreases with age equally in males and females. They observed that in males this decrease was compensated by increase in section modulus so that the overall strength of the shaft remained constant where as in females, the section modulus decreases with age, exacerbating the effects of material weakness and leading to greatly reduced femoral strength in old age. Stein et al. [80] investigated age-related and gender related differences in bone size and bone mechanics at the femoral diaphysis. They observed that the women had smaller bones, less cortical area and higher static stresses than men.

It is reported by Cordey et al. [20] that the number of fractures is three to four times larger for men than for women up to the age of 50 years and also three to five times larger for women than for men after 50 years of age. The increase in the number of fractures with age reported to be more 'flat' for men than for women.

\section{Effect of Rate of Deformation}

Melnis et al. [60] carried out an experimental study of the effect of deformation rate on the mechanical properties of human compact bone tissue upon tensile stressing which is the most dangerous form of stressing. The samples were taken from the middle portion of the diaphysis of the left tibia of nine males who died in accidents at ages from 20 to 30 years. They observed that the ultimate tensile stress increased with increasing deformation rate from $10^{-5}$ to $1 \mathrm{sec}^{-1}$ and the initial elastic modulus remained virtually constant. In the study by Katsamanis et al. [43], the Hopkinson bar stress technique and a universal testing machine had been used to investigate the dynamic and static mechanical properties of cortical bone taken from a human femur. Furthermore, it is observed that the Poisson's ratio did not exhibit any significant variation for the two different types of loading. It is reported that the
Young's Modulus and Ultimate tensile stress increased and the strain to failure decreased with increasing strain rate.

Courtney et al. [22] used elderly (mean age $73.5 \pm 7.4$ years $)$ and younger adults $(32.7 \pm 12.8$ years) cadaver femurs to investigate whether the strength, stiffness and energy absorption capacity of the femur increased under high deformation rate. They observed that for displacement rates of $100 \mathrm{~mm} / \mathrm{sec}$ the strength and stiffness increased about $20 \%$ and $100 \%$ respectively, compared with previous results from tests conducted at a strain rate of $2 \mathrm{~mm} / \mathrm{sec}$. They noted that because of the increased stiffness at the higher rate, there was no significant increase in energy absorption.

Ferreira et al. [30] investigated the mechanical properties of fresh bovine cortical bone at different strain rates using Split Hopkinson Pressure Bar (SHPB) method. They reported an increase in ultimate strength and a decrease in elastic modulus with an increase of strain rate for both longitudinal and transverse directions of the bone.

\section{Effect of Species and Location}

Saulgozis et al. [75] reported that the elastic deformation and strength properties of the compact bone tissue of the human tibia were non uniform both over the various zones of the cross section and along the length. One of the factors determining this difference in the mechanical properties is the non uniformity of the biochemical composition of the bone. Wang et al. [87] reported that the fracture toughness of bovine femoral bone is a function of sampling sites and crack orientations.

Brown et al. [88] studied the variation of toughness with anatomic sites. They observed that the femoral neck had a greater resistance to crack initiation in both tension and shear-loading modes than the femoral diaphysis.

\section{Fracture toughness of bone}

Fracture toughness has been shown to be a good index to assess the mechanical performance of bone by Yan et al. [92]. Fracture toughness measures material's resistance to fracture when a crack like defect is present. It has been suggested that the fracture toughness provides a better index regarding the mechanical performance of bone than strength or elongation at fracture by Bonfield [10]. There is a considerable interest in cracking of a bone because the cracks can grow 
to cause fracture in bones (known clinically as 'stress fractures'); a practical problem which occurs frequently in human subjects (e.g. athletes, dancers and army personnel) and in animals (e.g. race horses, battery chickens) by Hazenberg [37].

The fracture of bone is better characterized by linear-elastic fracture mechanics. In this case, for a linear-elastic material, any inelastic (e.g., yielding) behavior is limited to a small distance near the tip region, and the stress and displacement fields local to the tip of a preexisting crack are described by the stress-intensity factor, K. The stress-intensity factor, $\mathrm{K}$ may be defined for mode I (opening mode), mode II (shear loading), and mode III (tearing or anti shear loading) in terms of the geometrical crack configuration, applied stress, $\sigma_{\text {app }}$, and crack size, $\mathbf{a}$ as follows:

$$
\mathrm{K}_{(\mathrm{I}, \mathrm{II}, \mathrm{III})}=\mathrm{Q} \cdot \sigma_{\text {app. }}(\pi \mathrm{a})^{1 / 2}
$$

where: $\mathrm{Q}$ is a dimensionless parameter dependent on component and crack geometry as well as loading mode (i.e., mode I, II, or III) as shown in Figure 1. by Knott (44). The resistance to fracture is then defined for a particular mode of loading as the critical value of the stress intensity factor, $\mathrm{K}_{\mathrm{IC}}, \mathrm{K}_{\mathrm{IIC}}$ or $\mathrm{K}_{\text {IIIC }}$ at the onset of unstable fracture.

An alternative fracture mechanics description, which has also been used in studies on the toughness of bone, expresses toughness in terms of a critical value of the strain-energy release rate, $\mathrm{G}_{\mathrm{C}}$, defined as the change in potential energy per unit increase in crack area at fracture, which may be expressed as:

$$
G_{C}=\frac{p_{C}^{2} d C}{2 B d a}
$$
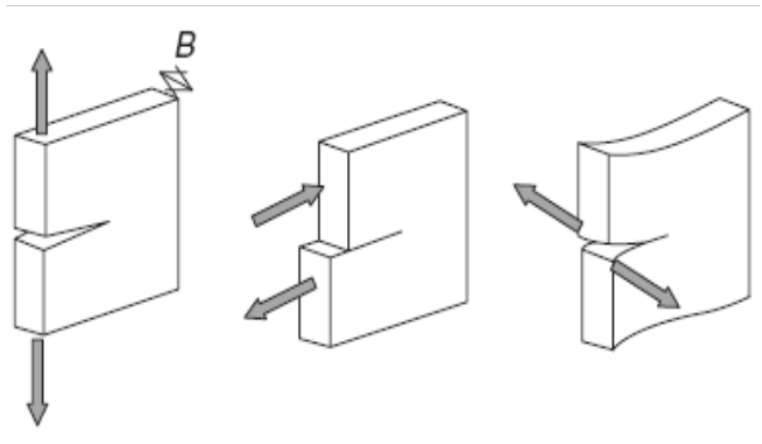

Mode I

Mode II

Mode III

Fig. 1. Different modes of loading: mode I (opening mode), mode II (shear loading), and mode III (tearing or antishear loading) from Knott [44] where: $\mathrm{P}_{\mathrm{C}}$ is the critical load, $\mathrm{B}$ the specimen thickness, and $\mathrm{dC} / \mathrm{da}$ is the change in sample compliance with crack extension (the compliance, $\mathrm{C}$, being the displacement per unit load). It is important to note that for linear-elastic materials, $\mathrm{G}$ and $\mathrm{K}$ are uniquely related as:

$$
G=\frac{K_{I}^{2}}{E^{\prime}}+\frac{K_{I I}^{2}}{E}+\frac{K_{I I I}^{2}}{2 G}
$$

where: $\mathrm{E}^{\prime}$ is the appropriate elastic modulus (E $=\mathrm{E}$ in plane stress, $\mathrm{E} /\left(1-v^{2}\right)$ in plane strain, where E is Young's modulus and $v$ is Poisson's ratio), and $G$ is the shear modulus. If linear-elastic conditions prevail (i.e., inelastic deformation is limited to a small zone near the crack tip), both $\mathrm{G}_{\mathrm{C}}$ and $\mathrm{K}_{\mathrm{C}}$ should give a geometry-independent measure of toughness, provided plane-strain conditions are met, as described below.

In applying fracture mechanics, the specimen thickness, B, may affect the measured toughness values as loading conditions change from a state of plane strain to that of plane stress. Plane strain here refers to a condition where the outof-plane strain is essentially zero, whereas with plane stress, the out-of-plane stress is zero. If the sample has a thickness significantly larger than the scale of local inelasticity, $\mathrm{K}_{\mathrm{C}}$ or $\mathrm{G}_{\mathrm{C}}$ values should be thickness, geometry, and crack-size independent and a condition of plane strain is said to exist. However, with thinner specimens, the toughness values may be significantly higher and not independent of such factors as conditions approach that of plane stress. The ASTM standard for mode I fracture toughness testing of materials (i.e., ASTM E-399) requires that:

$$
B \geq 2.5\left(\frac{k_{I}}{\sigma_{y}}\right)^{2}
$$

for plane-strain conditions to exist, where $\sigma_{\mathrm{y}}$ is the yield stress of the material. As a result of variations in $\mathrm{K}_{\mathrm{IC}}$ and $\sigma_{\mathrm{y}}$ with factors such as species, location, and orientation, the condition in Equation 4 may not always be strictly met for fracture testing of cortical bone, particularly for human bone, which is of the most clinical interest. It should be noted, however, that Equation 4 is considered conservative for most engineering materials. However, Wright and Hayes [89] reported no thickness dependence for mode I longitudinal cracking in bovine femora for $1.8-3.8 \mathrm{~mm}$ thick specimens. 
The details of the orientation designation for the specimens are shown in Figure 2. The first letter in the designation refers to the direction normal to the crack plane, whereas the second letter refers to the direction of crack propagation. Behiri and Bonfield [7] also observed a similar conclusion for mode I fracture of bovine tibia, also in the longitudinal direction, where no thickness dependence was seen between 0.5 and $2 \mathrm{~mm}$.

Similar to most of the engineering materials, cortical bone shows the least resistance to fracture under mode I loading. Indeed, Norman et al. [63] had shown average ratios of $\mathrm{G}_{\mathrm{IIC}} / \mathrm{G}_{\mathrm{IC}}$ to be 12.7 for longitudinal fracture in human tibia for persons aged between 50 and 90 years. Similarly, Yeni and Norman [93] also reported higher $\mathrm{G}_{\text {IIC }}$ values relative to $G_{I C}$ for human femoral neck as well. As mode I fracture is the easiest failure mode, it has received the most attention in the literature. The anisotropy of the microstructure of compact bone in the major support bones, (i.e. with osteons aligned in a preferred orientation parallel to the longitudinal axis of the bone) produces a corresponding anisotropy in the fracture characteristics [1]. At a given strain rate, it requires a smaller stress or energy to fracture bone sections in the longitudinal direction (i.e. mainly between the osteons) than in the transverse direction (i.e. mainly across the osteons) [8]. Compact bone is also notch sensitive and the presence of surface cracks significantly reduces the energy absorbed during fracture for both longitudinal and transverse fracture directions by Nalla et al. [62].

Studies concerning the effect of orientation on the toughness of bone have shown transverse cracking directions (i.e., where the crack must cut the osteons) to be consistently tougher than orientations with longitudinal cracking, where the crack splits osteons along the longitudinal axis of the bone. Behiri and Bonfield [9] demonstrated a progressive increase in toughness from 3.2 to $6.5 \mathrm{MPa} \sqrt{\mathrm{m}}$ as the orientation of specimens was varied rotationally from the longitudinal to transverse cracking directions in the bovine tibia. Feng et al. [29] reported the $\mathrm{K}_{\mathrm{IC}}$ for transverse cracking to be twice of the longitudinal cracking in bovine femora. Similarly, Lucksanambool et al. [50] observed $\mathrm{K}_{\mathrm{IC}}$ for transverse orientation of cracking to be twice of the longitudinal orientation of cracking in bovine tibia and femora. Furthermore, Phelps et al. [69] in their study on baboon femora showed an even larger effect of

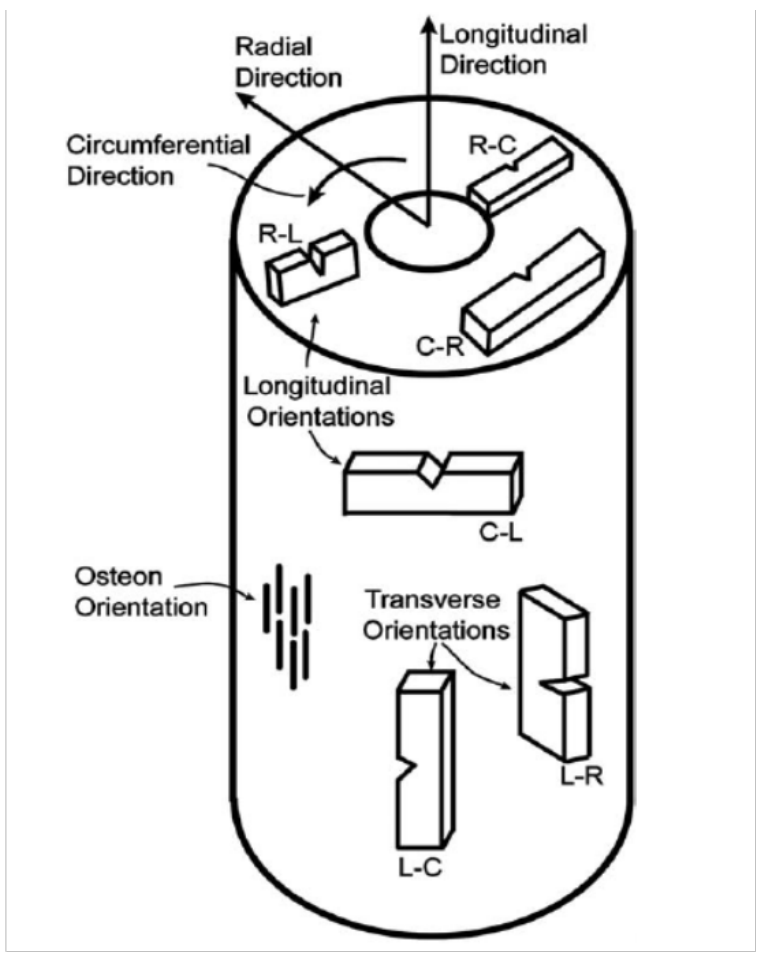

Fig. 2. The orientation code used by the ASTM E399 fracture toughness standard

[ASTM E-399 (1997)]

orientation, with a mean $\mathrm{K}_{\mathrm{IC}}$ for fracture in the transverse direction to be around 3.5 times higher than that of the longitudinal direction. Finally, Nalla et al. [61] observed similar behavior in human humeri, with cracks kinking approximately $90^{\circ}$ toward the longitudinal direction when cracking in the transverse direction was attempted, with transverse toughness reported to be 1.5 times that of the longitudinal.

\section{MINIATURE SPECIMEN TEST TECHNIQUE}

\section{Various Miniature Specimen Tests}

A good number of approaches have been given by researchers in literature for developing a miniature specimen test technique. This includes straightforward scaling down of standard specimen geometry (such as miniaturization of Charpy V notch specimen and tensile specimen etc.) in combination with a test technique which could be used on a small volume specimen. An important consideration in specimen miniaturization is, whether the results from miniaturized testing match the data from standard tests or at 
least can be scaled by a well founded correlation which holds good for a variety of materials and testing conditions. The various test techniques proposed in literature include instrumented microhardness test, bulge test, shear punch test, indentation method, creep and load relaxation test and miniaturized fracture tests for obtaining strength, ductility, time-dependent flow and fracture behavior on specimens as small as those used in TEM (Transmission Electron Microscope). Kundan Kumar et al. [46] presented a comparative study of methods used for evaluation of mechanical properties of materials using miniature and sub-size tensile test specimens and established the potential of miniature tensile tests which can be useful for life estimation of any inservice-equipment and for development of new materials. Both these applications intend to use very small amount of material for evaluation of the mechanical properties. Jürgen Olbricht et al. [65] discussed a miniature creep specimen test method that uses small scale specimens $(3 \mathrm{~mm}$ diameter) which can be extracted from thinwalled power plant components like e.g. superheater tubes. In this way, creep property variations resulting from manufacture and heat treatments of the component or the exposure to stress, temperature and atmospheres during service can be captured. Quang-Bang Tao et al. [83] focused on the design of a micro-testing machine used for evaluating the mechanical properties of solder alloys. The different parts of the testing device have been developed and assembled in a manner that will facilitate the study of miniature solder joints as used in electronic packaging.

\section{Small Punch Test Technique and Prediction of Strength Property}

Small punch test technique (using miniature specimens) has been extensively employed for the evaluation of mechanical properties in metallic alloys. This is used to extract mechanical properties (tensile properties and fracture toughness etc.) from disk type specimens. In this technique, a supported disk or coupon is loaded with a penetrator of particular geometry until the failure occurs. The output of the test is in the form of a load-displacement curve which is analyzed for getting the mechanical properties. Although different researchers attempted with different penetrator geometry, the use of spherical and cylindrical geometries are quite common. The test carried out with the spherical indenter is called "ball punch test" and the one with the cylindrical indenter is called "shear punch test".

Ball punch test is of two types: "disk bend test" and "bulge test". In general, disk bend refers to a test in which the disk specimen is simply supported and in bulge test the specimen is clamped between the two dies using a fixed number of screws. The initial use of the ball punch test was an attempt made by Manahan et al. [51, 52], in which a disk of $3 \mathrm{~mm}$ diameter and $0.25 \mathrm{~mm}$ thickness was used where the disk got displaced axially by a hemispherical punch of $1 \mathrm{~mm}$ diameter.

Apart from strength and ductility properties, there have also been attempts to obtain fracture and impact data from small punch test. Baik et al. [3] used penetrators with different tip geometries to punch the small coupon of ferritic steel over a range of temperature. The optimum tip geometry was found to be $2.4 \mathrm{~mm}$ diameter ball. Mao and Takahashi [54] investigated the deformation behaviour using small punch test. They also used recrystallization-etch technique and semi analytical method to find equivalent fracture strain. They proposed an empirical correlation for yield strength $\left(\sigma_{\mathrm{y}}\right)$ as:

$$
\sigma_{y}=0.36 \frac{P_{y}}{t_{0}^{2}}
$$

where: $\sigma_{\mathrm{y}}$ is yield strength (in $\mathrm{MPa}$ ) and $\mathrm{P}_{\mathrm{y}}$ is the load at breakaway from linearity (in N) and $t_{0}$ is the original thickness of small specimen (in mm). Further, Mao et al. $[55,56]$ used small punch test to determine the yield and ultimate strength on irradiated specimens of size $10 \mathrm{~mm} \times 10$ $\mathrm{mm} \times 0.5 \mathrm{~mm}$ as well as subsized compact tension $(\mathrm{CT})$ specimens to measure the fracture toughness.

$\mathrm{Xu}$ and Zhao [91] used a modified miniature specimen test where the mechanical properties were obtained by analyzing elastic-plastic bulge deformation behaviour of a circular plate specimen loaded at the centre. Following empirical relation was obtained, where the terms have the usual meaning:

$$
\sigma_{y}=0.477 \frac{P_{y}}{t_{0}^{2}}
$$

Foulds et al. [33] used small punch test to estimate the fracture toughness of the components 
in the fossil power plants. Foulds and Viswanathan [34] described a technique for material removal and a test approach for in-service integrity assessment of power plants etc by using the small punch test to estimate the tensile properties and the fracture toughness.

Kameda et al. [41] used small punch test on disk specimens of $6 \mathrm{~mm}$ diameter and $0.50 \mathrm{~mm}$ thickness with the hemispherical punch having tip diameter of $2.4 \mathrm{~mm}$ which was used to investigate the mechanical properties of $\mathrm{CoNi}$ CrAlY coating on gas turbine blades. Fong and Fraser [31] developed a small ellipsoidal shape punch to evaluate the mechanical properties of anisotropic Zircaloy-2 tube material which was further employed to find the burst properties of the tube.

Foulds et al. [33] used the miniature disk bend test to successfully estimate the conventional tensile and fracture properties of steel reactor pressure vessel using specimens of $6.35 \mathrm{~mm}$ diameter and $0.5 \mathrm{~mm}$ thickness. Similarly Geary and Dutton [35] used small punch test on $3 \mathrm{~mm}$ diameter discs of structural steels and relationships were developed to obtain tensile properties, fracture toughness etc. Lee et al. [49] developed a small punch test using rectangular specimens to determine the fracture energy.

Brookfield et al. [95] employed the small punch test and bulge test to determine the material properties and also used the finite element analysis for simulation purpose. Finite element model was used to establish a relationship between the yield stress and the punch force $(\mathrm{F})$ for elastic-perfectly plastic situation as:

$$
\sigma_{y}=\frac{F+49.20}{2.35 \times 10^{-6}}
$$

where: $\sigma_{\mathrm{y}}$ is in $\mathrm{MPa}$ and $\mathrm{F}$ is in $\mathrm{N}$.

Song et al. [79] used small punch test (0.5 mm thickness) and subsize Charpy test to estimate the temper embrittlement of neutron irradiated 2.25Cr-1Mo steel. Karthik et al. [42] employed the shear punch test to determine the mechanical properties of heat affected zone (HAZ) formed in $2.25 \mathrm{Cr}-1 \mathrm{Mo}$ weldments and established a correlation to obtain the tensile properties. Zidan and Brookfield [95] determined the post yield material properties of stainless steel from the small punch test by comparing the experimental curve with a large set of previously determined finite element curves for different post yield properties.

Husain [39] employed small punch test on different steels (H11 steel, D3 steel, structural steel) having varying strength to establish a general relationship to obtain yield strength using circular, rectangular and square shaped specimens with three different hemispherical punches. The empirical equations proposed for the determination of yield strength are shown in Table 1. Eskner and Sandstrom [29] obtained the yield strength of steels from small punch test by analyzing the initial elastic deformation with the use of classical bending theory.

Table 1. Empirical equations for yield strength for various shapes of the miniature specimen [39]

\begin{tabular}{|c|c|}
\hline Shape of the Specimen & Yield strength in $\mathrm{MPa}$ \\
\hline Circular & $\sigma_{y}=1.50 \frac{P_{y}}{\pi t_{0}^{2}}(1+v)\left[\ln \frac{R}{r}+\left(\frac{r}{2 R}\right)^{2}\right]$ \\
\hline Square & $\sigma_{y}=1.50 \frac{P_{y}}{\pi t_{0}^{2}}(1+v)\left[\ln \left(\frac{a}{2 r}\right)\right]$ \\
\hline Rectangular & $\sigma_{y}=0.75 \frac{P_{y} l}{b t_{0}^{2}}$ \\
\hline
\end{tabular}

Where: $v=$ Poisson's ratio $=0.3, r=0.80 r_{0}, r_{0}=$ tip radius of hemispherical headed punch in $\mathrm{mm}, r=$ the contact tip radius of rigid punch up to yielding in $\mathrm{mm}, \mathrm{R}=$ radius of the sample in $\mathrm{mm}, \sigma_{\mathrm{y}}=$ Yield strength in $\mathrm{MPa}, \mathrm{P}_{\mathrm{y}}=$ Load at breakaway from linearity in $\mathrm{N}, a=$ side of square shape specimen in $\mathrm{mm}, \mathrm{t}_{0}=$ original thickness of the specimen in $\mathrm{mm}, I=$ length of rectangular shape specimen in $\mathrm{mm}, b=$ width of rectangular specimen in $\mathrm{mm}$ 
Wang et al. [88] conducted small punch test on reactor vessel steel using miniature specimens of varying thickness i.e. $0.4 \mathrm{~mm}, 0.5 \mathrm{~mm}, 0.63 \mathrm{~mm}$, $0.75 \mathrm{~mm}, 0.86 \mathrm{~mm}$ and $1 \mathrm{~mm}$. They proposed empirical correlations for the yield strength and ultimate tensile strength based on the results of small punch test is as follows:

$$
\begin{gathered}
\mathrm{P}_{\mathrm{u}}=0.644 \times 2 \pi \mathrm{rt}_{\mathrm{o}} \sigma_{\mathrm{u}}+202.17 \\
\mathrm{P}_{\mathrm{y}}=0.15 \times 2 \pi \mathrm{rt} \sigma_{\mathrm{y}}+94.37
\end{gathered}
$$

where: $r$-radius of the specimen in $\mathrm{mm}, \mathrm{t}_{\mathrm{o}}$ - thickness of the specimen, $\mathrm{P}_{\mathrm{u}}, \mathrm{P}_{\mathrm{y}}$ are ultimate load and yield load in $\mathrm{N}$ and $\sigma_{\mathrm{u}}$ and $\sigma_{\mathrm{y}}$ are ultimate strength and yield strength in MPa.

$\mathrm{Hu}$ and Ling [38] conducted small punch test on Zirconium using disc specimens of diameter $=10 \mathrm{~mm}$ and thickness $=0.5 \mathrm{~mm}$ to evaluate the mechanical properties. They had also implemented 3D finite element simulation to model the plastic damage of Zirconium. They observed a good agreement between load-displacement curves of finite element simulation and small punch tests.

\section{Prediction of Fracture Toughness Using Miniature Specimen Test Technique}

The most commonly used parameter for characterizing the fracture toughness of materials is the plane strain fracture toughness, $\mathrm{K}_{1 \mathrm{C}}$, which is based on linear elastic fracture mechanics. However, for low strength-high toughness materials, the specimen size for plane strain becomes unduly large. In such cases, the J-integral parameter, $\mathrm{J}_{1 \mathrm{C}}$, based on elastic-plastic fracture mechanics is an attractive alternative.

The experimental correlation between equivalent fracture strain $\left(\varepsilon_{\mathrm{qf}}\right)$ and the fracture toughness $\left(\mathrm{J}_{\mathrm{IC}}\right)$ based on the single specimen technique proposed by Takahashi et al. [82] is linear and is given below:

$$
\mathrm{J}_{\mathrm{IC}}=280 \varepsilon_{\mathrm{qf}}-50
$$

where $\mathrm{J}_{\mathrm{IC}}$ is in $\mathrm{kJ} / \mathrm{m}^{2}$.

It is important to find the relationship between the biaxial fracture strain and the fracture toughness, $\mathrm{J}_{\mathrm{IC}}$, for engineering purposes. However, the relation between fracture toughness and biaxial fracture strain contains the yield strength and work hardening coefficient terms. For the relationship of fracture toughness with the fracture strain of ductile materials, Bayoumi and Bassim [5] proposed empirical relation:
$J_{t c}=S \rho^{*} \varepsilon_{\mathscr{w}} f\left(E, K, n, \varepsilon_{y}\right)+2 \sigma_{f}^{2} \pi L_{t}^{*} \frac{(1-v)}{E}$

Here $S$ is the shape factor characterizing the geometry of plastic zone which is approximated to be 1.0 and $\rho^{*}$ is the Neuber's micro support effect constant which is approximated to be $0.025 \mathrm{~mm}$. The $\mathrm{L}_{\varepsilon}^{*}$ is a characteristic distance which depends on the microstructure of the material, $\mathrm{f}\left(\mathrm{E}, \mathrm{K}, \mathrm{n} \varepsilon_{\mathrm{y}}\right)$ is a function determined from the stress vs. strain relationship of the material, $\sigma_{\mathrm{f}}$ and $\mathrm{E}$ are fracture stress and elastic modulus respectively.Mao et al. [54] estimated the biaxial fracture strain from small punch test based on the ductility of the material as:

$$
\varepsilon_{q f}=0.15\left(\frac{\delta^{*}}{t_{\circ}}\right)^{1.5}
$$

where: $\delta^{*}$ is the measured displacement at fracture and $t_{0}$ is the original thickness of the small punch test specimen in $\mathrm{mm}$. Mao et al. [54] conducted a number of studies on a range of materials which indicated that the fracture toughness was related to the biaxial fracture strain by the expression:

$$
\mathrm{J}_{\mathrm{IC}}=427 \varepsilon_{\mathrm{qf}}-205
$$

where: $\mathrm{J}_{\mathrm{IC}}$ is in $\mathrm{kJ} / \mathrm{m}^{2}$.

The fracture toughness $\mathrm{K}_{\mathrm{IC}}$ for brittle materials has been found to be a function of fracture stress $\left(\sigma_{\mathrm{f}}\right)[55]$ as follows:

$$
\mathrm{K}_{\mathrm{IC}}=0.07\left(\sigma_{\mathrm{f}(\mathrm{sp})}\right)^{2 / 3}
$$

where: $\mathrm{K}_{\mathrm{IC}}$ is in $\mathrm{MPa} \vee \mathrm{m}$ and $\sigma_{\mathrm{f}}$ is in $\mathrm{MPa}$.

Suzuki et al. [81] also reported a linear trend for a $2.25 \mathrm{Cr}-1 \mathrm{Mo}$ steel between fracture toughness $\mathrm{J}_{\mathrm{IC}}$ and fracture strain $\varepsilon_{\mathrm{qf}}$ as follows:

$$
\mathrm{J}_{\mathrm{IC}}=357 \varepsilon_{\mathrm{qf}}-121
$$

where: $\mathrm{J}_{\mathrm{IC}}$ is in $\mathrm{kJ} / \mathrm{m}^{2}$. A few years later Mao et al. [56] reported a larger number of data points where the relationship could best be described by the expression:

$$
\mathrm{J}_{\mathrm{IC}}=339 \varepsilon_{\mathrm{qf}}-119
$$

where: $\mathrm{J}_{\mathrm{IC}}$ is in $\mathrm{kJ} / \mathrm{m}^{2}$.

Lee et al. [49] recorded the following relationship for fracture toughness in plain carbon steels:

$$
\mathrm{J}_{\mathrm{IC}}=370 \varepsilon_{\mathrm{qf}}-40
$$

where: $\mathrm{J}_{\mathrm{IC}}$ is in $\mathrm{kJ} / \mathrm{m}^{2}$. At the same time Geary and Dutton [35] carried out work on similar 
steels and arrived at the expression:

$$
\mathrm{J}_{\mathrm{IC}}=123 \varepsilon_{\mathrm{qf}}+135
$$

where: $\mathrm{J}_{\mathrm{IC}}$ is in $\mathrm{kJ} / \mathrm{m}^{2}$. Saucedo-Munoz et al. [74] proposed a correlation between $\mathrm{J}_{\mathrm{IC}}$ and $\varepsilon_{\mathrm{qf}}$ for cryogenic austenitic stainless steel as:

$$
\mathrm{J}_{\mathrm{IC}}=(1304.1 \pm 85) \varepsilon_{\mathrm{qf}}+8.09
$$

where: $\mathrm{J}_{\mathrm{IC}}$ is in $\mathrm{kJ} / \mathrm{m}^{2}$.

Husain [39] conducted small punch test on three different shapes of specimens viz. circular, square and rectangular and developed empirical correlations for the predictions of fracture toughness as a function of equivalent fracture strain for the different geometries. The proposed correlation is given in Table 2.

Partheepan et al. [68] estimated the fracture toughness of in-service materials using dumbbell shaped miniature specimen tensile test and artificial neural network model. They found the fracture toughness by giving the miniature test load-displacement diagram as the input to the artificial neural network model. Zhang et al. [94] conducted shear punch test on nano structured silver to measure its fracture toughness using discs of $11.5 \mathrm{~mm}$ diameter and $1 \mathrm{~mm}$ thickness.

\section{APPLICATION OF FINITE ELEMENT METHOD (FEM) TO MINIATURE TESTING}

\section{Simulation of Miniature Test Using FEM}

Application of finite element method in the field of miniature specimen test has attracted attention of many researchers. There are two approaches using FEM namely forward or direct approach and reverse or inverse approach. The forward approach is to model the miniature specimen using the known material properties and getting the results like load - displacement curve, stress - strain diagram etc. whereas the inverse method is applied to extract material properties from the resultant miniature test results. In this section the direct approach will be discussed.

The direct finite element modeling of the miniature specimen test is carried out by using the available material property data as input. This is done on a number of specimens made out from different materials. The output from the finite element modeling and corresponding input material properties are kept as a data base. For an unknown material the miniature test is carried out experimentally. The result from the experimental test is recorded for that unknown specimen and compared against the available finite element data base. The input material properties of an output, which is closer to the experimental test result is considered to be the property of the unknown material.

Manahan [53] performed finite element analysis to convert miniature disk bend test experimental load - deflection curve into useful stress-strain curve and for obtaining information on ductility using ABAQUS. The miniature disk bend test contains material, geometric and boundary nonlinearity. Out of these, the boundary non-linearity had not been adequately addressed in general purpose finite element code at that time. He proposed a new finite element frictional contact boundary condition model to accurately analyze the miniature disk bend test using FEM.

Foulds et al. [32] used large deformation finite element analysis of small punch test to mea-

Table 2. Empirical equations for the prediction of fracture toughness and fracture strain for different geometries

\begin{tabular}{|c|c|c|}
\hline Shape of the Specimen & Fracture Toughness $\left(\mathrm{kJ} / \mathrm{m}^{2}\right)$ & Equivalent Fracture Strain \\
\hline Circular & $J_{I C}=722.28\left(\varepsilon_{q f}\right)^{2.837}$ & $J_{I C}=631.30\left(\varepsilon_{q f}\right)^{2.916}$ \\
\hline Square & $J_{I C}=631.30\left(\varepsilon_{q f}\right)^{2.916}$ & $\varepsilon_{q f}=1.566\left[\ln \left(\frac{t_{\circ}}{t^{*}}\right)\right]^{1.027}$ \\
\hline Rectangular & $J_{I C}=707.02\left(\varepsilon_{q f}\right)^{2.799}$ & $\varepsilon_{q f}=3.627\left[\ln \left(\frac{t_{\circ}}{t^{*}}\right)\right]^{1.248}$ \\
\hline
\end{tabular}

Where: $\mathrm{t}^{*}$ is the minimum thickness at fracture in $\mathrm{mm}$ and $\mathrm{t}_{\mathrm{o}}$ is the original miniature specimen thickness in $\mathrm{mm}$. 
sure the critical strain energy density. They carried out finite element analysis of small punch test using commercially available Lawrence Livermore National Laboratory NIKE2D code. The absorbed strain energy density at the observed crack initiation location was computed. In order to account for the change of contact between the punch head and the small specimen's top surface, a sliding interface was used.

The deformation mode varies successively during the small punch test and the deformation is not homogeneous in the specimen. This complexity led to the development of empirical correlation between small punch test results and those of conventional tests. The load at breakaway from initial linearity has been correlated with yield stress. Cheon and Kim [17] used small punch test to estimate the yield stress from the initial deformation behaviour of a nuclear pressure vessel steel and $12 \mathrm{Cr}$ turbine rotor steel. They used $\mathrm{t} / 100$ offset method to find out the load at breakaway point. They also carried out FEM of small punch test using the commercially available ABAQUS code. The load-displacement curve obtained by FEM simulation of small punch specimen was used to find the yield stress.

Eck and Ardell [27] used the controlled-flaw method in conjunction with the miniature disk bend test to measure the fracture toughness of the intermetallic alloy Ti-Al containing $\mathrm{Cr}, \mathrm{Nb}$, and $\mathrm{W}$ and heat-treated to produce a duplex microstructure. This method required knowledge of the fracture stress which could not be calculated analytically for disk-shaped specimens deforming plastically prior to failure. The fracture stress was therefore determined using the finite element program NIKE2D, along with the elastic constants of Ti-Al, the measured yield stress and the published tensile stress-strain curve as input information.

Brookfield et al. [95] used the finite element analysis to understand the behaviour of specimens under the punch and the bulge test and obtained force-displacement curve, Von-Mises stress, equivalent plastic strain and vertical deflections of the upper and lower surface of the disk specimen. A relationship between the yield stress and punch force was obtained for elastic-perfectly plastic material.

Husain et al. [39] used small punch test and conducted 3D finite element modeling using ABAQUS to find out the effect of punch diameter on the load-displacement diagram. Three hemispherical headed punches were used to conduct the small punch test on circular disk specimen having $10 \mathrm{~mm}$ diameter and $0.5 \mathrm{~mm}$ thickness which was clamped along the circumference.

\section{Inverse Finite Element Technique for Miniature Tests}

The inverse problem has attracted the attention of many researchers in diverse number of fields. Inverse problem entails determining unknown causes based on observation of their effects. This is in contrast to the direct problem, whose solution involves finding effects based on a complete description of their causes.

A simple illustration may highlight the distinction. In particle dynamics, the motion of a mass in a gravitational field depends completely on the initial position and velocity of the object. The physical description of the process ( $\mathrm{F}=\mathrm{mg}$ ) and the corresponding initial conditions (position $\mathrm{x}_{0}$ and velocity $\mathrm{V}_{0}$ ) constitute the causes of the ensuing motion. If these causes are fully described, the resulting motion can be found. This motion (described as the vector $\mathrm{x}(\mathrm{t}))$ is the effect of these causes.

Now one inverse problem can be seen. Suppose we know the mass of the object and the strength of the gravitational field in which it moves. By observation (experiment), we also acquire knowledge of the position and/or velocity of the object at several known instants of time. An inverse problem can now be formulated in the form of a question: Can the initial position and velocity of the body be determined?

Hainsworth et al. [36] used an alternative approach to analyze the shapes of the nano-indentation curve and thus quantitatively model the relationship between Young's modulus, indentation hardness, indenter geometry and the resultant maximum displacement for a given load.

Beghini et al. [6] used numerical approach for the evaluation of the stress-strain curve for metallic materials starting from the results of instrumented spherical indentation test. They modeled spherical indentation process by means of finite element for materials having different $\sigma-\varepsilon$ curves. By means of proper use of these results, they developed an iterative procedure, which allows the $\sigma-\varepsilon$ curve to be obtained with satisfactory accuracy for a large number of materials.

Dao et al. [25] had undertaken a comprehensive computational study to identify the extent to which elasto-plastic properties of ductile materials could be determined from instrumented sharp 
indentation. They carried out large deformation finite element computations using ABAQUS for 76 different combinations of elasto-plastic properties that encompass a wide range of parameters commonly found in pure metals and alloys. In this study, the Young's modulus was varied from 10 to $210 \mathrm{GPa}$, yield strength from 30 to 3000 $\mathrm{MPa}$, strain hardening exponent from 0 to 0.5 and the Poisson's ratio was kept fixed at 0.3 . They used dimensional analysis to construct a new set of dimensionless functions to characterize instrumented sharp indentations. Forward and reverse analysis algorithms were thus established; the forward algorithms allow for the calculation of a unique indentation response for a given set of elasto-plastic properties, whereas the reverse algorithms enable the extraction of elasto-plastic properties from a given set of indentation data. The plastic properties of materials obtained from instrumented indentation were found to be sensitive to even small variations in the indentation load-depth responses.

Extending Dao's approach, Bucaille et al. [13] studied the influence of the included angle of conical indenters and the friction coefficient on the force penetration curves based on finite element analysis on elasto-plastic materials. Based on this analysis, they suggested a more general method for determining the plastic properties of metals. They have shown that friction has a significant effect on the normal force measured on tips having included angles lower than or equal to $50^{\circ}$. The accuracy of the results was improved by using sharper indenter.

DiCarlo et al. [26] presented a method for determining the stress-strain relationship of a material from hardness values obtained from the cone indentation tests with various apical angles. The properties such as Young's modulus, yield strength and the work-hardening exponent could be determined.

Lee et al. [48] proposed a simple experimental and computational method to determine stressstrain curves based on finite element modeling of nanoindentation. The method was verified using bulk Al by comparing the stress-strain curves obtained from tensile testing and applied to $\mathrm{Al}$ thin films deposited on a Si substrate.

Husain et al. [39] performed an experimental and a computational study of small punch test using circular disk shaped miniature specimen (10 $\mathrm{mm}$ diameter, $0.5 \mathrm{~mm}$ thickness) through inverse finite element procedure using ABAQUS com- puter code for the determination of constitutive tensile behavior of materials. The proposed inverse technique was based on the small punch experimental load vs. displacement curve. By using the output of experimental small punch test, they traced constitutive stress-strain curves through inverse technique. The computed constitutive stress-strain curves are compared with the curves obtained from a standard conventional tensile test and the results obtained for all the three cases demonstrated the effectiveness of the inverse procedure.

Partheepan [66] proposed an experimental and a numerical study of miniature specimen test using dumb-bell shaped specimen to determine the tensile properties based on inverse finite element procedure.

Cheon and Joo [18] determined the flow stress of structural materials used in nuclear and fossil power plants using the small punch test and inverse procedure. The methodology adopted in their study was comparison of experimental loaddisplacement response of small punch test with the one obtained by finite element simulation.

\section{CONCLUSION}

To the best of our knowledge, it is evident from the review presented in this paper that no work has been reported for evaluation of mechanical properties and fracture toughness in bones using miniature specimen technique. The miniature small punch test appears to be the best method existing at present which is capable of providing the several mechanical properties of materials and components. Direct evaluation of the material properties requires destructive testing of large number of standard size specimens. Acquiring standard size specimens from bones are very difficult since bones come in different shapes and sizes, and none have the geometry and gross morphology of an ideal mechanical test specimen. In fact, the irregular shape and the small size of the bone make conventional material testing difficult to apply and interpret. The miniature specimen test technique has been evolved to meet this challenge. Knowledge of mechanical properties of bones is essential for designers of prosthetic devices. The possibility of determining these properties by miniature specimens is particularly interesting since it would allow designers to personalize and so improve the design of prosthesis. 
The advantage of such miniature specimens includes the possibility of sampling very small volume of material within a heterogeneous structure such as cortical bone. This may also be used for studying biological materials that are not available in large enough volumes for conventional mechanical testing.

\section{REFERENCES}

1. An Y.H. and Draughan R.A. Mechanical testing of bone and the bone-implant interface. CRC Press, Boca Raton, Florida, USA, 1999.

2. ASTM E-399(97). Test method for plane-strain fracture toughness of metallic materials. Annual book of ASTM standards, ASTM International, Pa, 1997.

3. Baik J.K., Kameda J. and Buck O. Development of small punch tests for ductile-brittle transition temperature measurement of temper embrittled $\mathrm{Ni}-\mathrm{Cr}$ steel in the use of small scale specimens for testing irradiated material, ASTM STP 888, ASTM international, $\mathrm{Pa}, 1986,92-110$.

4. Bathe K.J. Finite element procedures. Prentice Hall of India Private Limited. New Delhi, India, 1996.

5. Bayoumi M.R. and Bassim M.N. Study of the relationship between fracture toughness $\left(\mathrm{J}_{\mathrm{IC}}\right)$ and bulge ductility. International Journal of Fracture, 23, 1983, 71-79.

6. Beghini M., Bertini L. and Fontanari V. Evaluation of the flow curve of metallic materials by means of spherical indentation. Computational and Experimental Methods, 5, 2001, 241-252.

7. Behiri J.C. and Bonfield W. Fracture mechanics of bone-the effects of density, specimen thickness, and crack velocity on longitudinal fracture. Journal of Biomechanics, 17, 1984, 25-34.

8. 8. Behiri J.C. and Bonfield W. Orientation dependence of the fracture mechanics of cortical bone. Journal of Biomechanics, 22, 1989, 863-872.

9. Behiri J.C. and Bonfield W. Crack velocity dependence of longitudinal fracture in bone. Journal of Materials Science, 15, 1980, 1841-1849.

10. Bonfield W. Advances in the fracture mechanics of cortical bone. Journal of Biomechanics, 20, 1987, 1071-1081.

11. Brookfield D.J., Li W., Rodgers B., Mottershead J.E., Hellen T.K., Jarvis J., Lohr R., Howard-Hildige R., Carlton A. and Whelan M. Material properties from small specimens using the punch and bulge test. Journal of Strain Analysis for Engineering Design, 34(6), 1999, 423-435.

12. Brown C.U., Yeni Y.N., and Norman T.L. Fracture toughness is dependent on bone location - a study of the femoral neck, femoral shaft, and the tibial shaft. Journal of Biomedical Materials Research, 49, 2000, 380-389.

13. Bucaille J.L., Staussb S., Felderc. E. and Michlera J. Determination of plastic properties of metals by instrumented indentation using different sharp indenters. Acta Materialia, 51(6), 2003, 1663-1678.

14. Burstein A.H., Currey J.D., Frankel V.H. and Reilly D.T. The ultimate properties of bone tissue: the effects of yielding. Journal of Biomechanics, 5, 1972, 31-44.

15. Carter D.R. and Hayes W.C. Fatigue life of compact bone-I: effects of stress amplitude, temperature and density. Journal of Biomechanics, 9, 1976, 27-34.

16. Carter D.R. and Hayes W.C. Compact bone fatigue damage-I. residual strength and stiffness. Journal of Biomechanics, 10, 1977, 325-337.

17. Cheon J. S. and Kim I. S. Initial deformation during small punch testing. Journal of Testing and Evaluation, 24(4), 1996, 255-262.

18. Cheon J. S. and Joo C. H. Small punch test for determining a flow stress by using a hybrid inverse procedure. Computational Materials Science, 43, 2008, 744-751.

19. Chittibabu V., Sehgal D.K. and Pandey R.K. Experimental and numerical studies on mechanical behaviour of bovine cortical bone using miniature specimen technique. Proc. of International Symposium for on Metallurgy, Materials Science and Engineering, Indian, Institute of Technology, Chennai, India, 2008, 18-23.

20. Cordey J., Schneider M. and Buhler M. The epidemiology of fractures of the proximal femur. Int. J. Care, 31, 2000, 56-61.

21. Courtney A. C., Watchel E. F., Myers E. R. and Hayes, W.C. Effects of loading rate on strength of the proximal femur. Calcified Tissue International, 55, 1994, 53-58.

22. Courtney A.C., Hayes W.C. and Gibson L.J. Age related differences in post-yield damage in human cortical bone: experiment and model. Journal of Biomechanics, 29, 1996, 1463-1471.

23. Cowin S.C. The mechanical and stress adaptive properties of bone. Annals of Biomedical Engineering, 2, 1983, 263-295.

24. Currey J.D. Physical characteristics affecting the tensile failure properties of compact bone. Journal of Biomechanics, 23, 1990, 837-844.

25. 25. Dao M., Chollacoop N., Van Vliet K.J., Venkatesh T.A. and Suresh S. Computational modeling of the forward and reverse problems in instrumented sharp indentation. Acta Materialia, 49(19), 2001, 3899-3018.

26. DiCarlo A., Yang H.T.Y. and Chandrasekar S. 
Semi-inverse method for predicting stress-strain relationship from cone indentations. Journal of Materials Research, 18(9), 2003, 2068-2078.

27. Eck S.J. and Ardell A.J. Fracture toughness of Ti-46.5Al-2.1Cr-3.0Nb-0.2W from finite element analysis of miniaturized disk-bend test results. Intermetallics, 6(6), 1998, 471-477.

28. Eskner M. and Sandstrom R. Mechanical property evaluation using the small punch test. Journal of Testing and Evaluation, 32(4), 2004, 282-289.

29. Feng Z., Rho J., Han S. and Ziv I. Orientation and loading condition dependence of fracture toughness in cortical bone. Materials Science and Engineering C, 11, 2000, 41-46.

30. Ferreira F., Vaz M. A. and Simoes J. A. Mechanical properties of bovine cortical bone at high strain rate. Materials Characterization, 57, 2006, 71-79.

31. Fong W. L. and Fraser C. R. Evaluation of Ductility of Zircaloy-2 Materials Using a Small Ellipsoidal-Shaped Punch. ASTM STP 1329, ASTM International, Pa., 1998, 602-613.

32. Foulds J.R., Woytowitz P.J., Parnell T.K. and Jewett C.W. Fracture Toughness by Small Punch Testing, Journal of Testing and Evaluation, 23(1), 1995, 3-10.

33. Foulds J. R., Wu M., Srivastav S. and Jewett C. W. Fracture and tensile properties of ASTM crosscomparison exercise A533B steel by small punch testing. ASTM STP 1329, ASTM International, Pa., 1998, 557-574.

34. Foulds, J. R., and Viswanathan, R. Nondisruptive material sampling and mechanical testing. Journal of Nondestructive Evaluation, 15 (3 and 4), 1996, 151-162.

35. Geary W. and Dutton J. T. Prediction of fracture toughness properties from $3 \mathrm{~mm}$ diameter punch discs. ASTM STP 1329, ASTM International, Pa., 1998, 588-601.

36. Hainsworth S. V., Chandler H. W. and Page, T. F. Analysis of nanoindentation load-displacement loading curves. Journal of Materials Research, 11(8), 1996, 1987-1995.

37. Hazenberg J.G., Taylor D. and Lee T. C. Mechanisms of short crack growth at constant stress in bone. Biomaterials, 27, 2006, 2114-2122.

38. Hu R., Ling X. Three-dimensional numerical simulation on plastic damage in small punch specimen of zirconium. International Journal of Pressure Vessels and Piping, 86, 2009, 813-817.

39. Husain A. Determination of mechanical behaviour of materials using miniature specimen test technique and finite element method. Ph. D. Thesis, IIT Delhi, New Delhi, 2003.

40. Irwin G.R. Analysis of stresses and strains near the end of a crack traversing plate. Journal of Applied Mechanics, 6, 1957, 361-364.
41. Kameda J., Bloomer T.E., Sugita Y., Ito A. and Sakurai S. Mechanical properties of aluminized CoCrAlY coating in advanced gas turbine blades. Journal of Material Science and Engineering A, 234-236, 1997, 489-492.

42. Karthik V., Kasi Viswanathan K.V. and Baldev Raj. Determination of mechanical property gradients in heat-affected zones of ferritic steel weldments by shear-punch tests, small specimen test techniques: fourth volume ASTM STP 1418, ASTM International, Pa., 2002.

43. Katsamanis F. and Demetrios D.R. Determination of mechanical properties of human femoral cortical bone by the hopkinson bar stress technique. Journal of Biomechanics, 23, 1990, 1173-1184.

44. Knott J. F. Fundamentals of fracture mechanics, Butterworth and Co, London, 1976.

45. Kotha S.P. and Guzelsu N. Tensile behavior of cortical bone: dependence of organic matrix material properties on bone mineral content. Journal of Biomechanics, 40, 2007, 36-45.

46. Kumar, K., Pooleery, A., Madhusoodanan, K., Singh, R.N., Chakravartty, J.K., Dutta, B.K., and Sinha, R.K. Use of Miniature Tensile Specimen for measurement of mechanical properties. Procedia Engineering, 86, 2014, 899-909.

47. Lang S.B. Ultrasonic method for measuring elastic coefficients of bone and results on fresh and dried bovine bone. IEEE Trans. on Bio. Eng., 1970, 101-105.

48. Lee B., Choi Y., Lee Y., Kim J. and Dongil K. Determining stress-strain curves for thin films by experimental/ computational nanoindentation. Proc. Materials Research Society Symposium, Thin Films - Stresses and Mechanical Properties X, 795, 2003, 345-350.

49. Lee W.K., Metzger D.R., Donner A. and Lepik O.E. Use of a small punch test procedure to determine mechanical properties, ASTM STP 1329, ASTM International, Pa., 1998, 539-556.

50. Lucksanambool P., Higgs W.A.J., Higgs R.J.E.D., and Swain M.W. Fracture toughness of bovine bone: influence of orientation and storage media. Biomaterials, 22, 2001, 3127-3132.

51. Manahan M.P. A New post irradiation mechanical behavior test-the miniaturized disk bend test. Nuclear Technology, 63, 1983, 295-315.

52. Manahan M.P., Argon A.S. and Harling O.K. The development of a miniaturized disk bend test for the determination of post irradiation mechanical properties. Journal of Nuclear Materials, 104. 1981, 1545-50.

53. Manahan M.P., Browning A.E., Argon A.S. and Harling O.K. Miniaturized disk bend test techniques-development and application. ASTM STP 888, ASTM International, Pa., 1986, 17-49. 
54. Mao X. and Takahashi. H. Development of a further-miniaturized specimen of $3 \mathrm{~mm}$ diameter for tem disk small punch tests. Journal of Nuclear Materials, 150(1), 1987, 30-37.

55. Mao X., Saito M. and Takahashi H. Small punch test to predict ductile fracture toughness $\mathrm{J}_{\mathrm{IC}}$ and brittle fracture toughness $\mathrm{K}_{\mathrm{IC}}$. Scripta Metallurgica et Materialia, 25, 1991, 2481-2485.

56. Mao X., Takahashi H. and Kodaira T. Use of subsized specimen for evaluating the strength and fracture toughness of irradiated $2 \frac{1}{4} \mathrm{Cr}-1 \mathrm{Mo}$ steel. Journal of Engineering Materials and Technology, Transactions of the ASME, 114(2), 1992, 168-171.

57. Martin R.B. Determinants of the mechanical properties of bones. Journal of Biomechanics, 24, 1991, 79-88.

58. Martin R.B. and Atkinson P.J. Age and sex-related changes in the structure and strength of the human femoral shaft. Journal of Biomechanics, 10, 1977, 223-231.

59. Melnis A.E. and Knets I.V. Effect of moisture on the mechanical behavior of compact bone tissue. 4th All Union Conference on Engineering and Medical Biomechanics, Riga, 1980, 305-312.

60.60. Melnis A.E. and Knets I.V. Effect of the rate of deformation on the mechanical properties of compact bone tissue. 5th All Union Conference on Engineering and Medical Biomechanics, Riga, 1981, 512-517.

61. Nalla R.K., Kinney J.H. and Ritchie R.O. Mechanistic fracture criteria for the failure of human cortical bone. Nature Materials, 2, 2003, 164-168.

62. Nalla R.K., Kruzic J.J., Kinney J.H. and Ritchie R.O. Mechanistic aspects of fracture and r-curve behavior in human cortical bone. Biomaterials, 26, 2005, 217-231.

63. Norman T.L., Nivargikar S.V., and Burr D.B. Resistance to crack growth in human cortical bone is greater in shear than in tension. Journal of Biomechanics, 29, 1996, 1023-1031.

64. Nyman J.S., Roy A., Xinmei Shen, Rae L. Acuna, Jerrod H. Tyler, Xiaodu Wang the influence of water removal on the strength and toughness of cortical bone. Journal of biomechanics, 39, 2006, 931-938.

65. Olbricht, J., Bismarck, M., \& Skrotzki, B. Characterization of the creep properties of heat resistant 9-12\% chromium steels by miniature specimen testing. Materials Science and Engineering: A, 585, 2013, 335-342.

66. Partheepan G. Determination of mechanical properties of materials using newly developed dumbbell shaped miniature specimen and numerical techniques, Ph. D. Thesis, IIT Delhi, New Delhi, 2006.
67. Partheepan G., Sehgal D.K. and Pandey R.K. Design and usage of a simple miniature specimen test setup for the evaluation of mechanical properties. International Journal of Microstructure and Material Properties, 1(1), 2005, 38-50.

68. Partheepan G., Sehgal D.K. and Pandey R.K. Fracture toughness evaluation using miniature specimen test and neural network. Computational Materials Science, 44, 2008, 523-530.

69. Phelps J.B., Hubbard G.B., Wang X., and Agrawal C.M. Microstructural heterogeneity and the fracture toughness of bone. Journal of Biomedical Materials Research, 1(51), 2000, 735-741.

70. Reilly D.T. and Burstein A.H. The elastic and ultimate properties of compact bone tissue. Journal of Biomechanics, 8, 1975, 393-405.

71. Reilly D.T., Burstein A.H. and Frankel V.H. The elastic modulus for bone. Journal of Biomechanics, 7, 1974, 271-275.

72. Rho J.Y., Kuhn-Spearing L., and Zioupos P. Mechanical properties and the hierarchical structure of bone. Medical Engineering and Physics, 20(2), 1998, 92-102.

73. Sakai M. and Bradt R.C. Fracture toughness testing of brittle materials. International Materials Reviews, 38, 1993, 53-78.

74. Saucedo-Munoz M.L., Lie S.C., Hashida T., Takahashi $\mathrm{H}$. and Nakajima H. Correlation between $\mathrm{J}_{\text {IC }}$ and equivalent fracture strain determined by small punch tests in JN1, JJ1 and JK2 austenitic stainless steel. Journal of Cryogenics, 41, 2001, 713-719.

75. Saulgozis Zh.Yu., Slutskii L.I., Knets I.V. and Yanson A.Kh. Investigation of the relations between the various mechanical properties and the biochemical composition of human bone tissue. 1st All Union Conference on Engineering and Medical Biomechanics, Riga, 1975, 138-145.

76. Sedlin E.D. and Hirsh C. Factors effecting the determination of physical properties of femoral cortical bone. Acta Ortho. Scand., 37, 1966, 29-48.

77. Shindo Y., Yamaguchi Y. and Horiguchi K. Small punch testing for determining the cryogenic fracture properties of 304 and 316 austenitic stainless steels in a high magnetic field. Cryogenics, 44(11), 2004, 789-792.

78. Smith I.M. and Griffiths D.V. Programming the finite element method. John Wiley, West Sussex, England, 2004.

79. Song S., Foulkner R.G., Flewitt P.E.J., Smith R.F., Marmy P. and Victoria M. Irradiation Induced embrittlement of a $2.25 \mathrm{Cr} 1 \mathrm{Mo}$ steel. Journal of Nuclear Materials, 280, 2000, 162-168.

80. Stein M.S., Thomas C.D.L., Feik S.A., Wark J.D. and Clement J.G. Bone size and mechanics at the femoral diaphysis across age and sex. Journal of 
Biomechanics, vol 31, 1998, 1101-1110.

81. Suzuki M., Eto M., Fukaya K., Nishiyama Y., Kodaira T., Oku T., Adachi M., Umino A., Takahashi I., Misawa T. and Hamaguchi Y. Evaluation of toughness degradation by small punch (SP) tests for neutron-irradiated 2Cr-1Mo steel. Journal of Nuclear Materials, 179-181. 1991, 441-444.

82. Takahashi H., Khan M.A. and Suzuki M. A Single specimen determination of $\mathrm{J}_{\mathrm{IC}}$ for different alloy steels. Journal of Testing and Evaluation, 8, 1980, 63-69.

83. Tao, Q.B., Benabou, L., Vivet, L., Tan, K.L., Morelle, J.M., Le, V.N. and Ouezdou, F.B. A design of a new miniature device for solder joints' mechanical properties evaluation. Proc. of the Institution of Mechanical Engineers, Part C: Journal of Mechanical Engineering Science, 2016.

84. Ule B., Sustar T., Dobes F., Milicka K., Bicego V., Tettamanti S., Maile K., Schwarzkopf C., Whelan M.P., Kozlowski R.H. and Klaput J. Small punch test method assessment for the determination of the residual creep life of service exposed components: outcomes from an inter laboratory exercise. Nuclear Engineering and Design, 192(1), 1999, 1-11.

85. Vinz H. Changes in the mechanical properties of human compact bone tissue upon aging. 1st All Union Conference on Engineering and Medical Biomechanics, Riga, 1975, 659-663.

86. Wang X., Lankford J. and Agrawal C.M. Use of a compact sandwich specimen to evaluate fracture toughness and interfacial bonding of bone. Journal of Applied Biomaterials, 4, 1994, 315-323.

87. Wang X., Shen X., Li X., and Agrawal C.M. Agerelated changes in the collagen network and toughness of bone. Bone, 28, 2002, 1-7.

88. Wang Z.X., Shi H.J., Lu J., Shi P., Ma X.F. Small punch testing for assessing the fracture properties of the reactor vessel steel with different thicknesses. Nuclear Engineering and Design, 238, 2008, 3186-3193.

89. Wright T.M. and Hayes W.C. Fracture mechanics parameters for compact bone - effects of density and specimen thickness. Journal of Biomechanics, 10, 1977, 419-430.

90. Wright T.M. and Hayes W.C. Letter to the editor: comments on the elastic and ultimate properties of bone tissue. Journal of Biomechanics, 9, 1976, 744.

91. Xu Y. and Zhao Z. A modified miniature disk test for determining material mechanical properties. Journal of Testing and Evaluation, 23(4), 1995, 300-306.

92. Yan J., Clifton K.B., Mecholesky Jr J.J. and Reep R.L. Fracture toughness of manatee rib and bovine femur using a chevron-notched beam test. Journal of Biomechanics, 39, 2006, 1066-1074.

93. Yeni Y.N. and Norman T.L. Calculation of porosity and osteonal cement line effects on the effective fracture toughness of cortical bone in longitudinal crack growth. Journal of Biomedical Materials Research, 51, 2000, 504-509.

94. Zhang L., Elwazri A. M., Zimmerly T., Brochu M. Shear punch testing and fracture toughness of bulk nano structured silver. Materials and design, 30, 2009, 1445-1450.

95.Zidan A.A. and Brookfield D.J. A Technique for the determination of post-yield material properties from the small punch test. Journal of Strain Analysis for Engineering Design, 38(4), 2003, 367-370.

96.Zienkiewicz O.C. and Taylor R.L. Finite element method in engineering. McGraw Hill, 1-2, London, 1989. 